Some Factors Affecting The Rural People Participation in The Rural Development Programs and Projects in Some Villages of El-Gharbia Governorate (Model: Water Management Improvement Project)

Amany S. A. H. El Kholy

Researcher, Department of Rural Community Research, Agricultural Extension \& Rural Development Research Institute, Agricultural Research Center.

بعض العوامل المؤثرة على مشـاركة الريفيين فى برامج ومشـاريع التنمية الريفية ببعض قرى محافظة الغربية

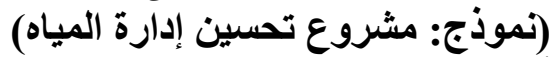

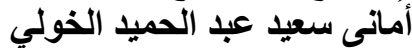
قسم بحوث المجتمع الريفى، معهد بحوث الإرشاد الزراعى والتنمية الريفية، مركز البحوث الزراعية الملخص

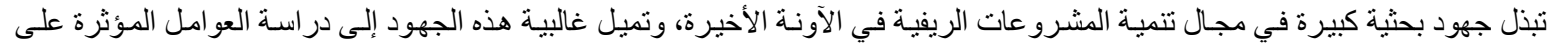

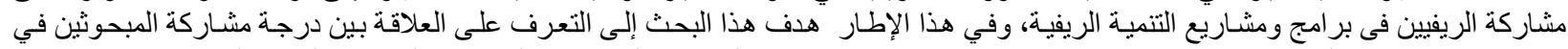

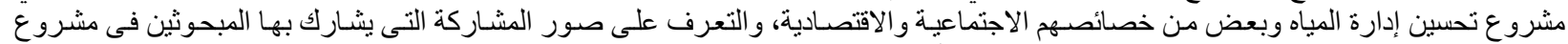

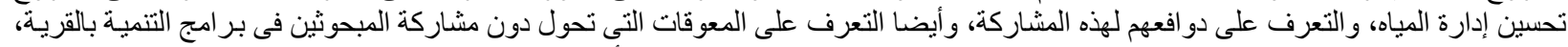

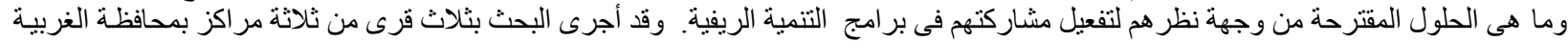

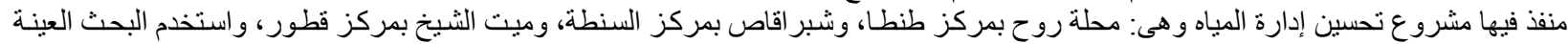

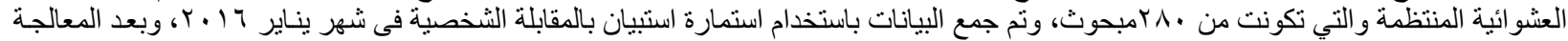

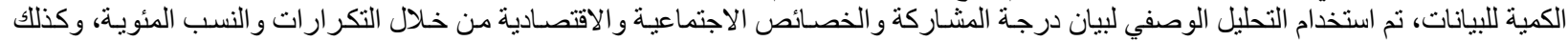

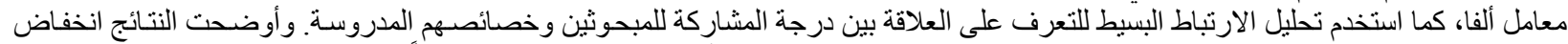

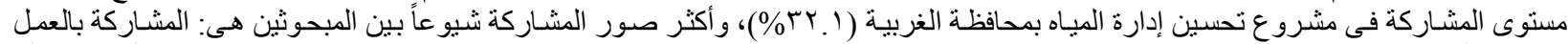

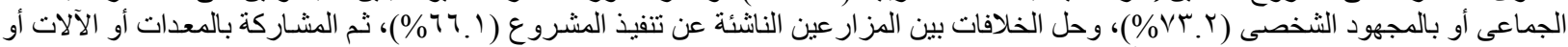

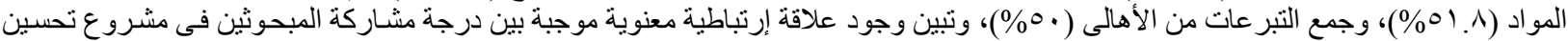

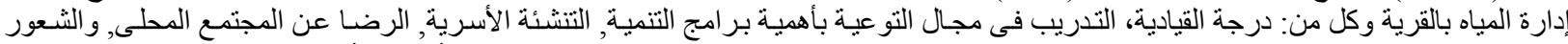

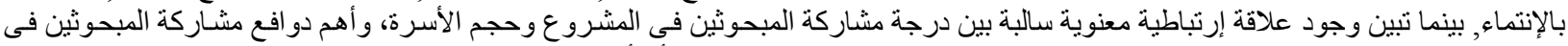

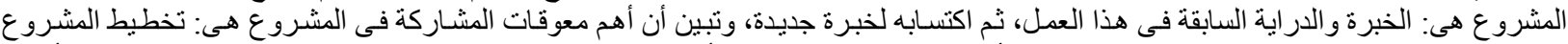

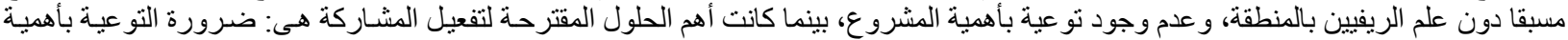

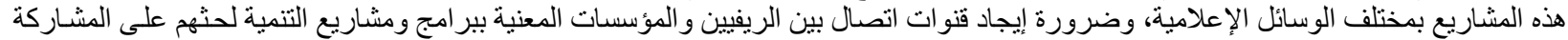

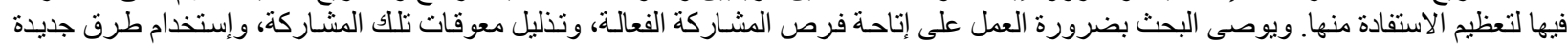

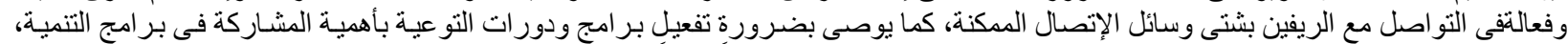

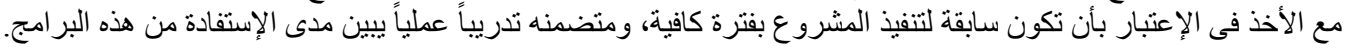

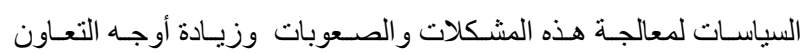
و التنسيق بين مختلف الأطر اف ذاف ذات الصلة الصنة بالعملية التنموية.

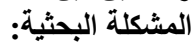

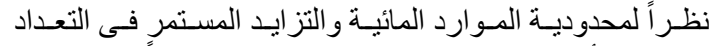

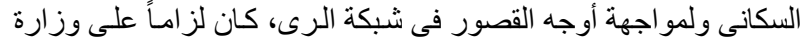

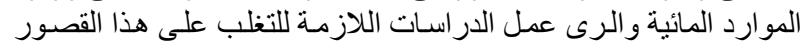

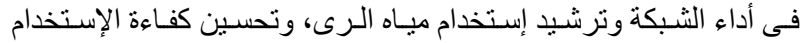

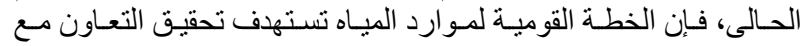

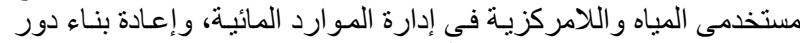

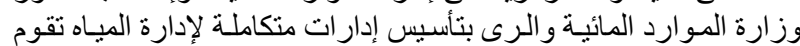

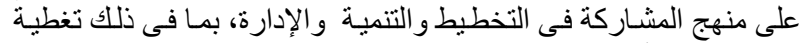

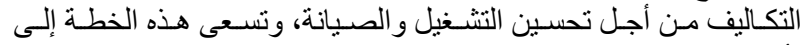

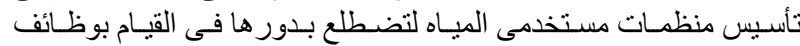

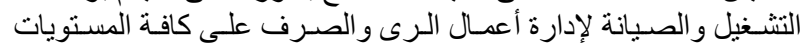

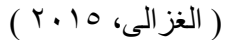

وتو اجه مصر عديد من التحديات في مجـال إدارة الموارد المائية

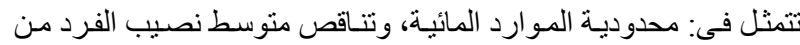

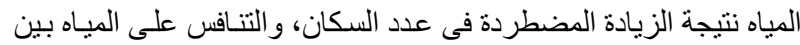

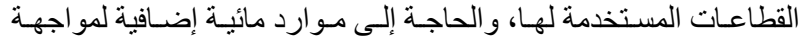

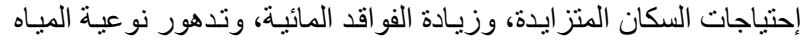

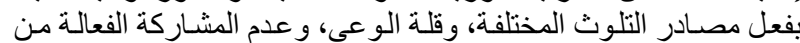

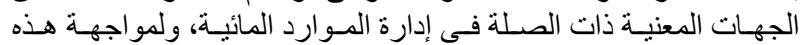

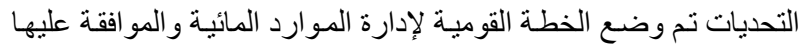

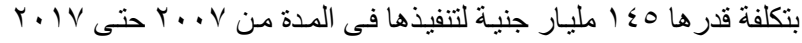

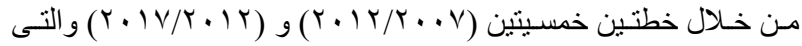

المقدمة

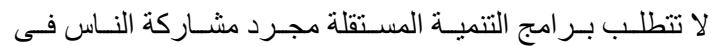

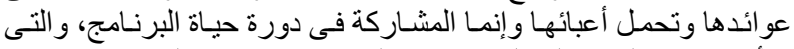

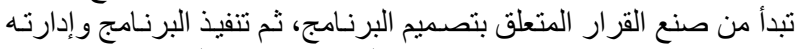

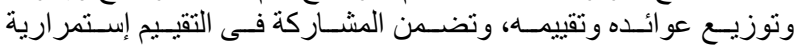

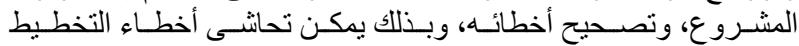

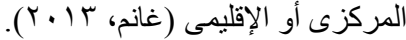

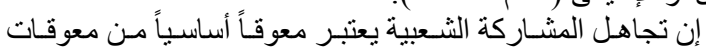

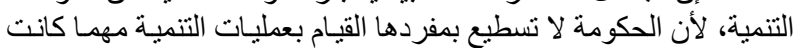

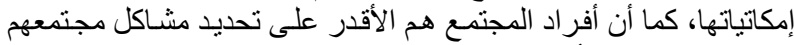

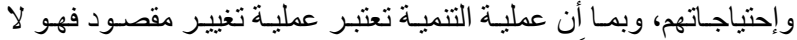

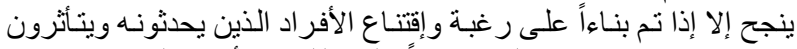

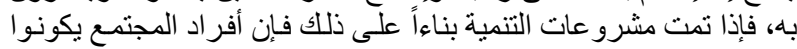

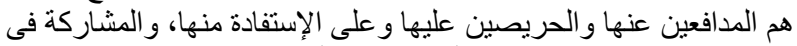

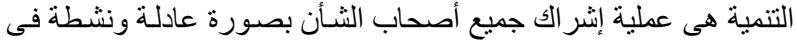

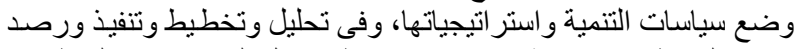

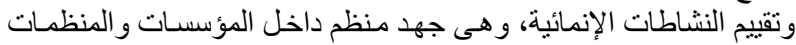

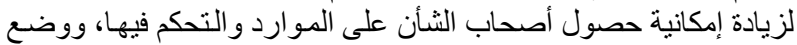

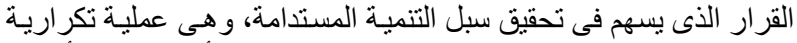

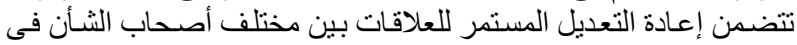

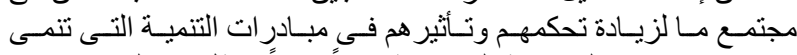

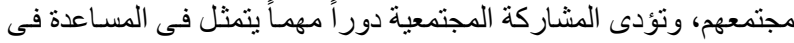

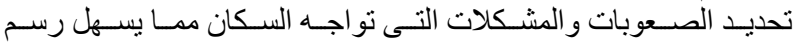


الإستعر اض المرجعى:

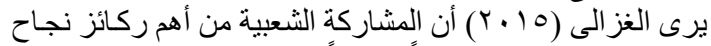

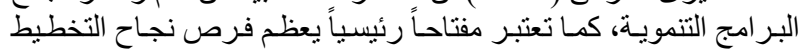

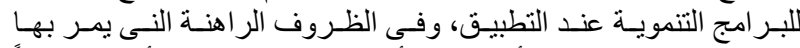

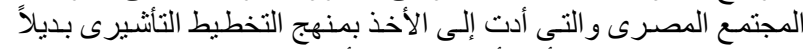

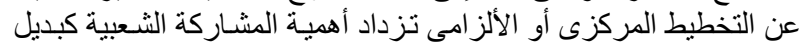

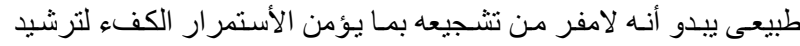

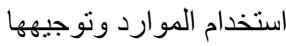

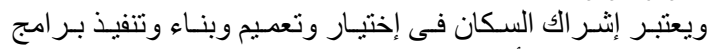

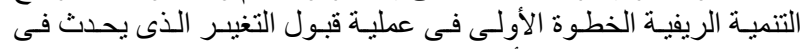

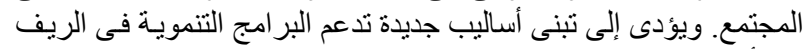

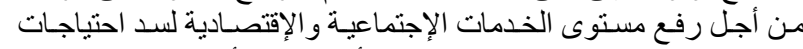

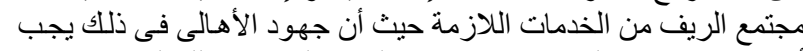

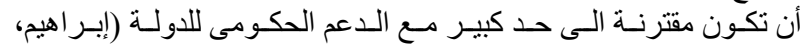

S

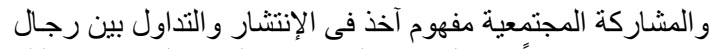

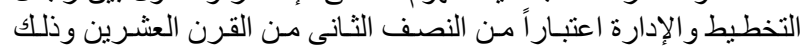

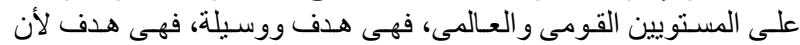

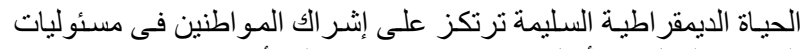

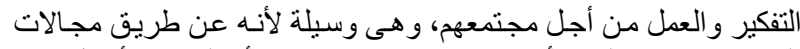

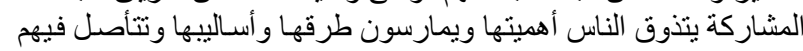

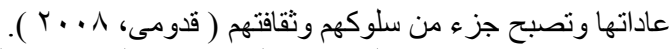

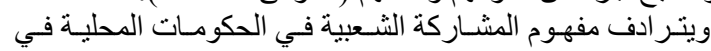

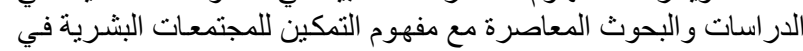

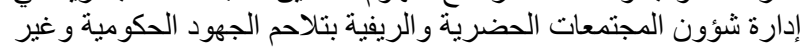

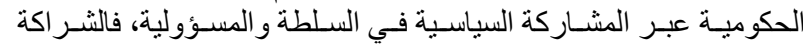

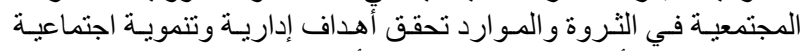

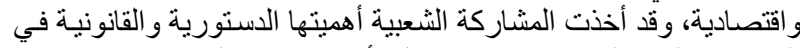

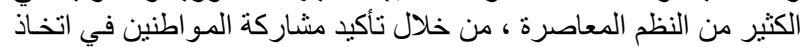

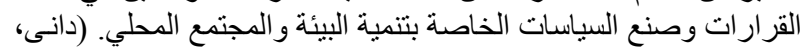

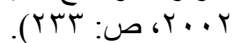

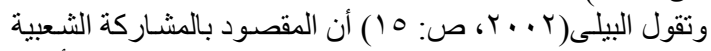

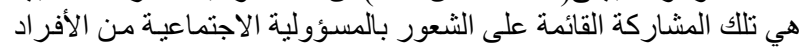

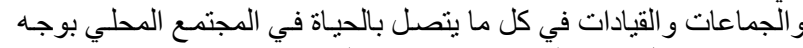

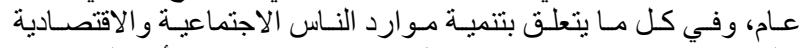

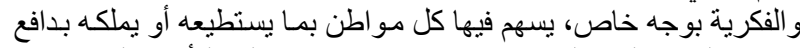

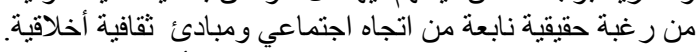

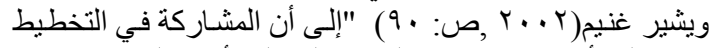

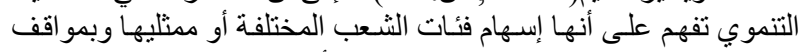

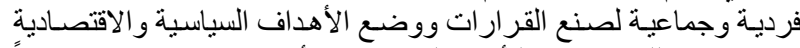

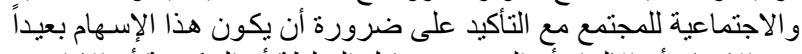

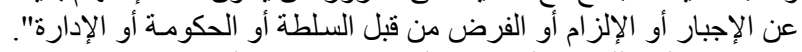

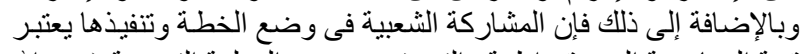

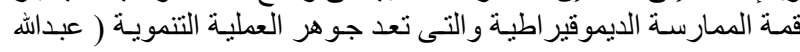
. (ro: 199 .

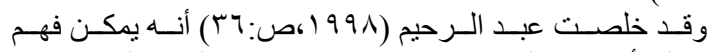

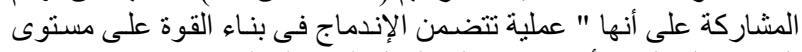

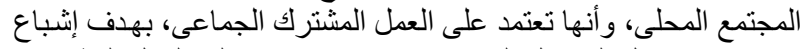

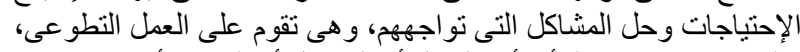

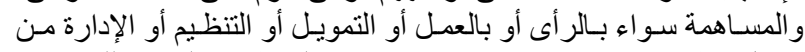

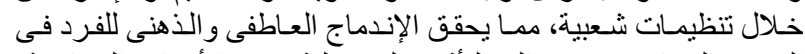

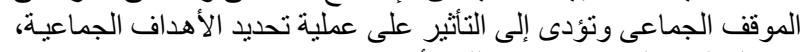

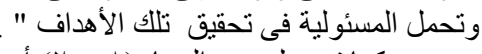

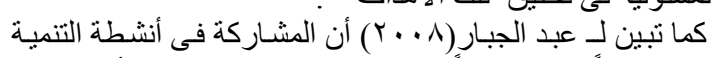

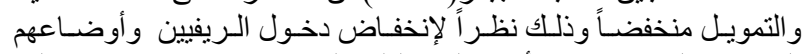

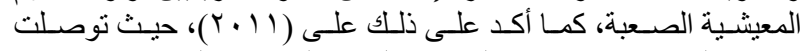

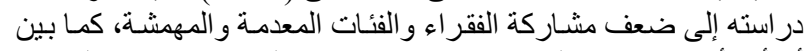

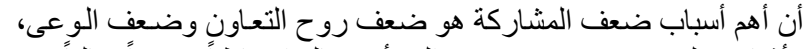

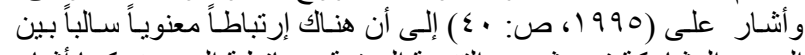

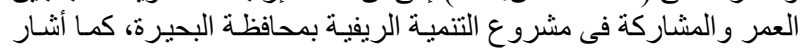

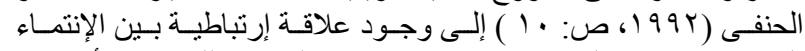

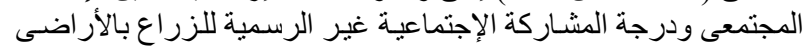

تهـف إلى زيـادة المـوارد المائيـة، ورفـع كفـاءة إستخدام المـوارد المائيـة

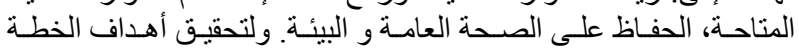

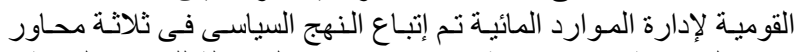

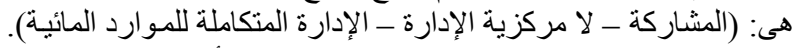

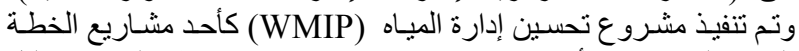

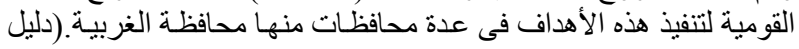

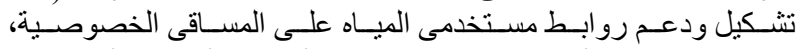

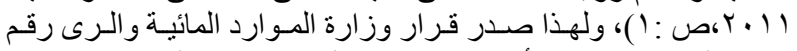

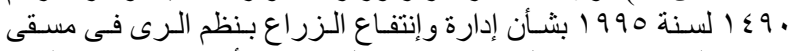

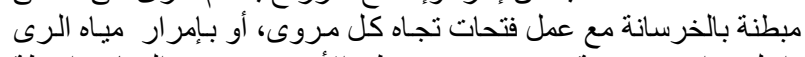

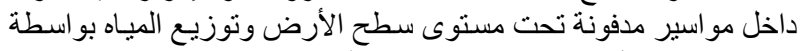

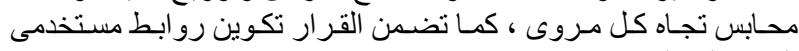

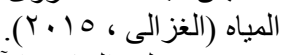

و على الجانب الآخر تعتبر المشـاركة الثـعبية فى جهود التنميـة

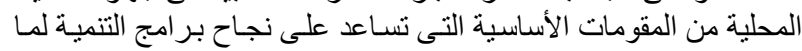

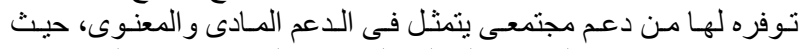

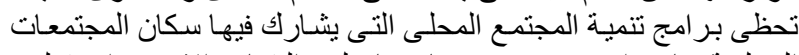

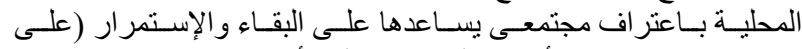

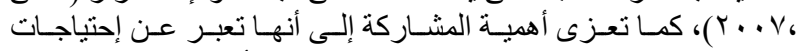

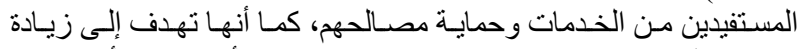

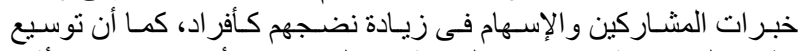

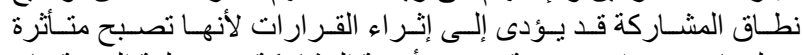

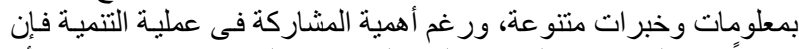

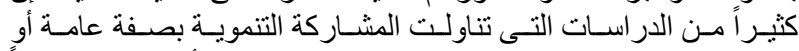

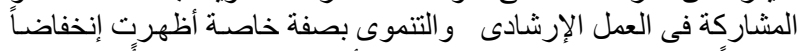

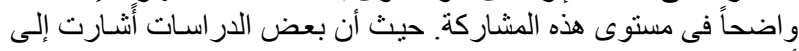

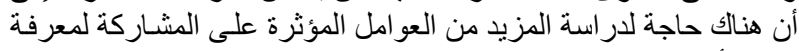

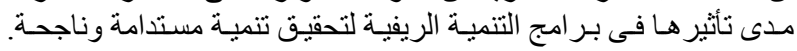

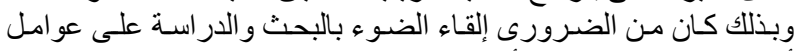

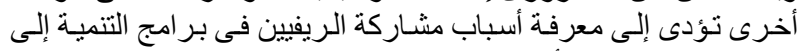

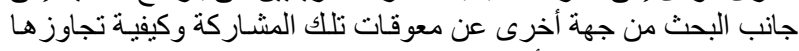
من وجهة نظر الريفيين أنفسهر.

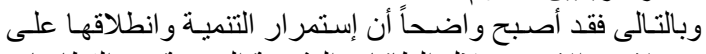

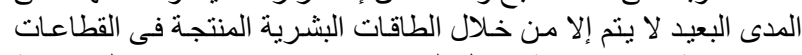

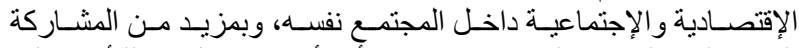

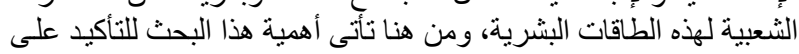

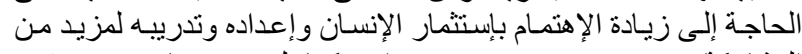

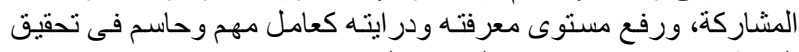

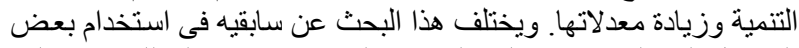

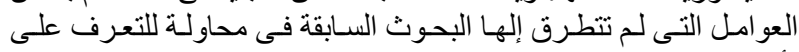

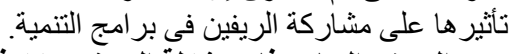

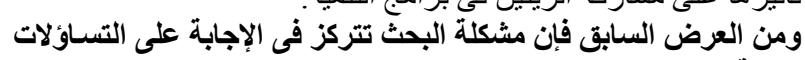
التالية:

ا ـما هى العو امل المؤثرة على مشاركة الريفين فى بر امج التنمية وخاصـة

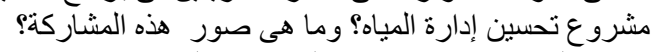

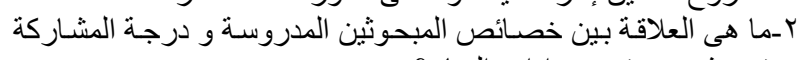

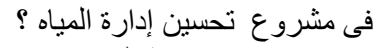

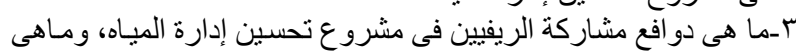

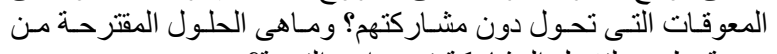

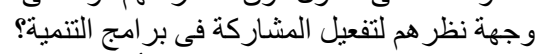

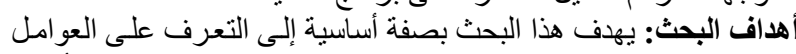

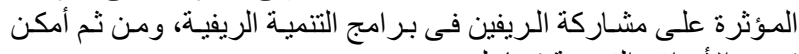

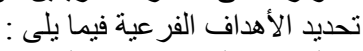

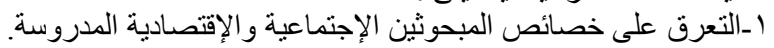

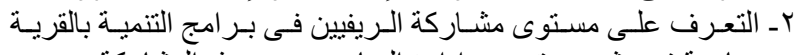

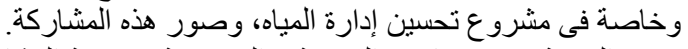

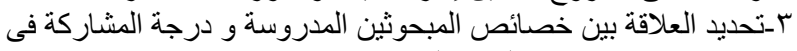
مشروع تحسين إدارة المياه بالقرية.

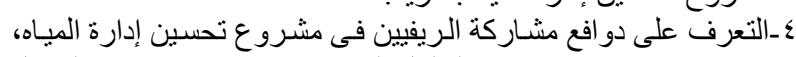

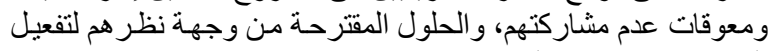
المشاركة فى بر امج التنمية. 


\section{J. Agric. Econom. and Social Sci., Mansoura Univ., Vol.7 (5), May, 2016}

القياس الكمى لمتغيرات الداراسة:

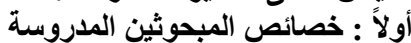

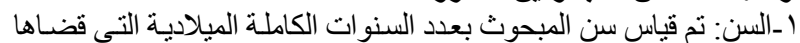

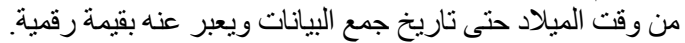

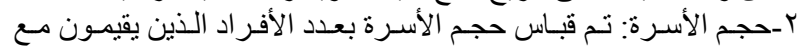

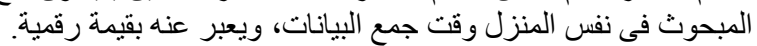

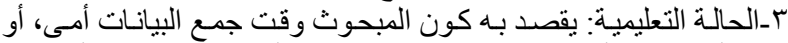

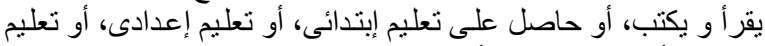

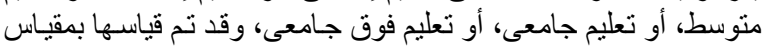

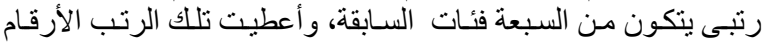

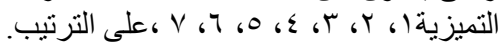

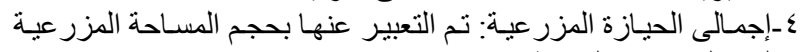

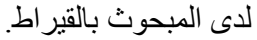

هـالدخل الأسرى الثهرى: تم التعبير عنهـ بـالرقم الخـام لأقرب جنيه بعد جمع جميع مصادر دخل الأسرة.

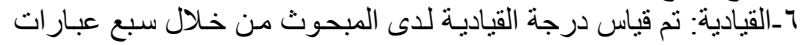

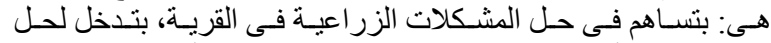

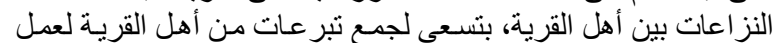

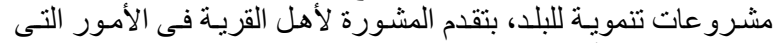

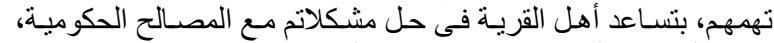

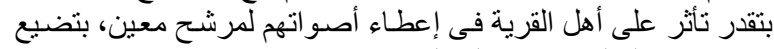

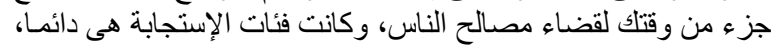

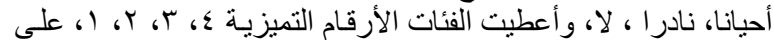

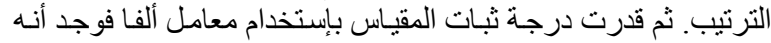

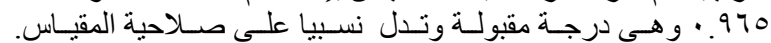

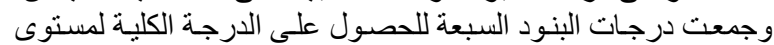

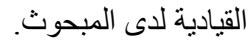

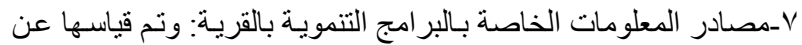

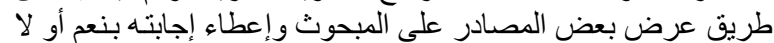

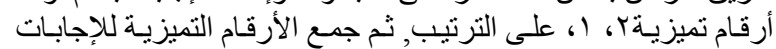

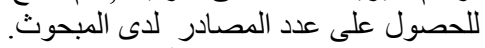

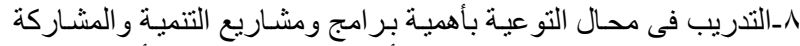

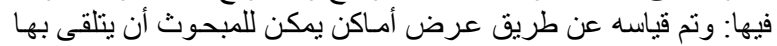

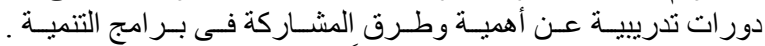

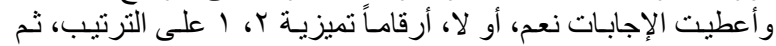

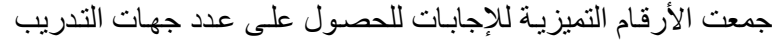

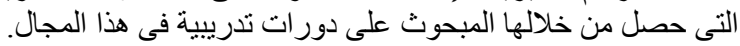

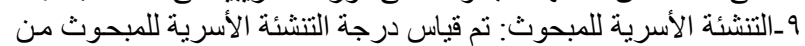

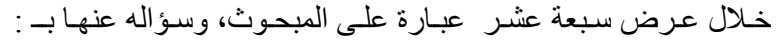

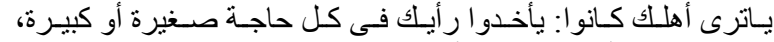

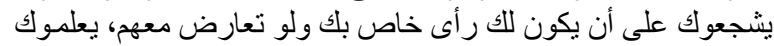

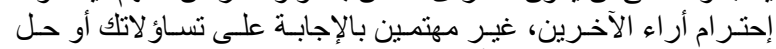

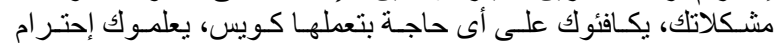

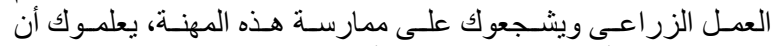

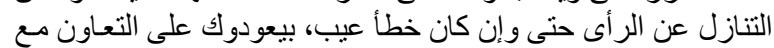

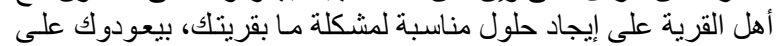

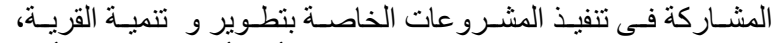

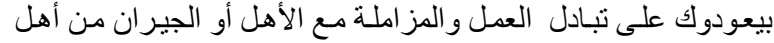

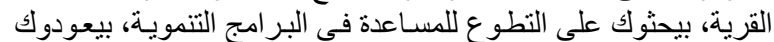

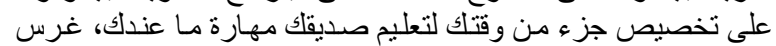

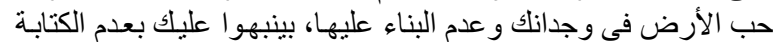

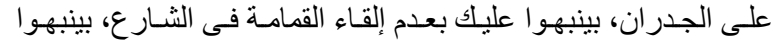

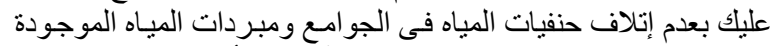

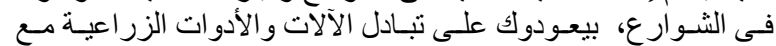

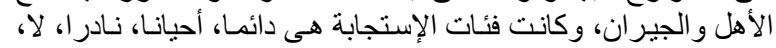

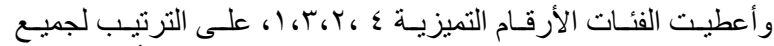

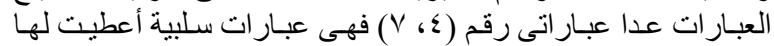

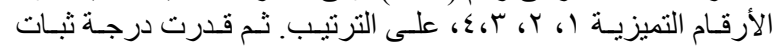

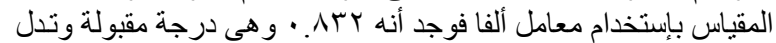

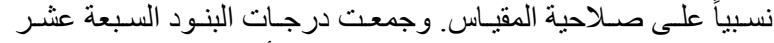
للحصول على الدرجة الكلية لمستوى التنشئة الأسرية للمبحوث.

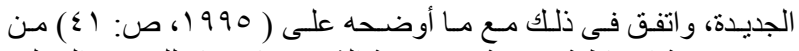

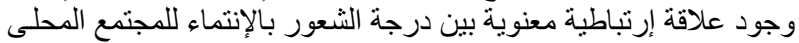

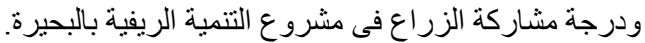

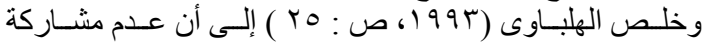

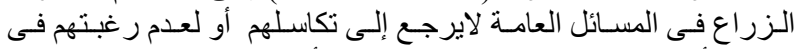

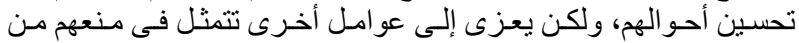

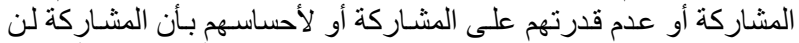

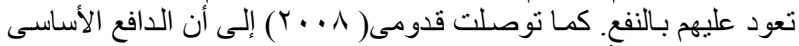

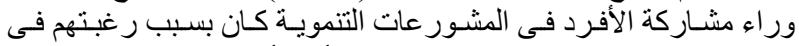

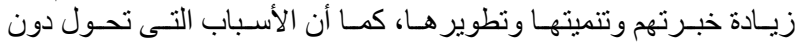

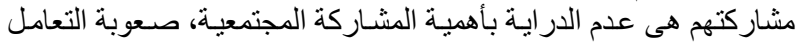

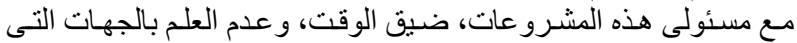
يمكن التطوع بها.

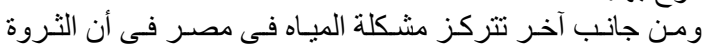

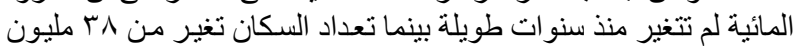

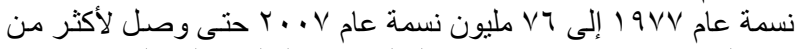

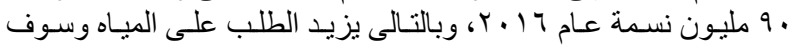

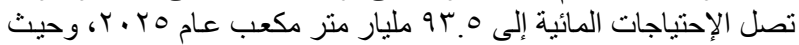

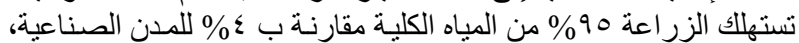

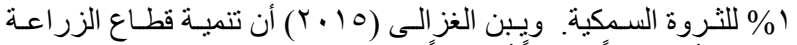

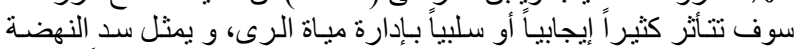

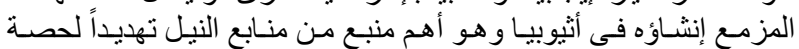

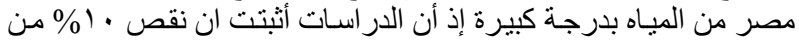

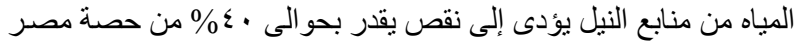

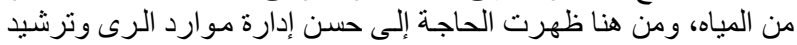

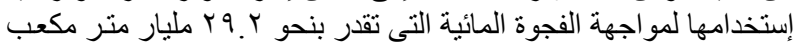

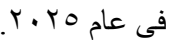

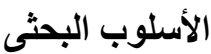

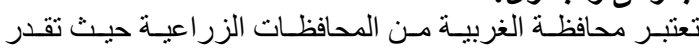

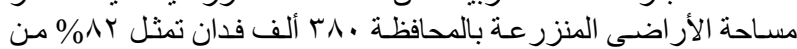

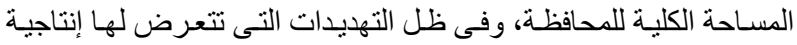

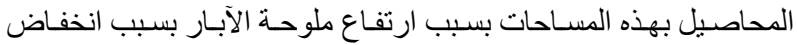

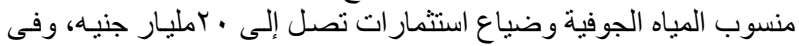

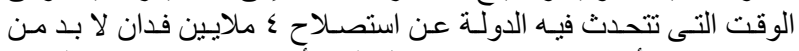

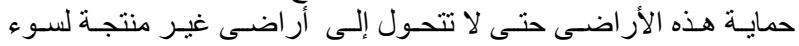

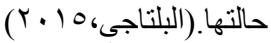
وقد أجريت هذه الدر اسة بالقرى المنفذ بها مشرو ع تحسين إدارة

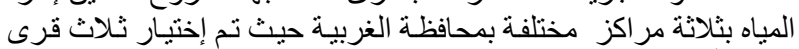

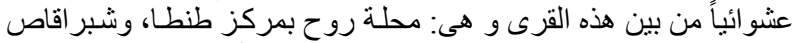

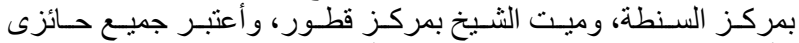

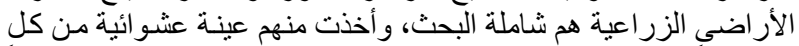

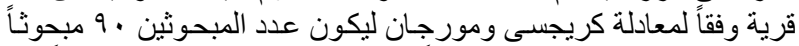

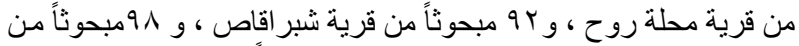

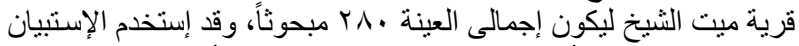

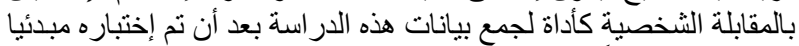

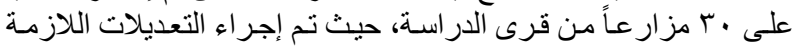

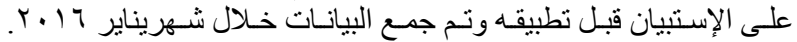

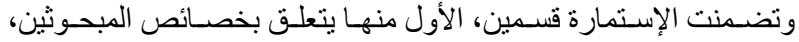

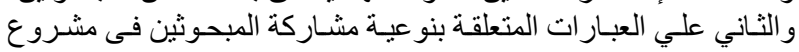

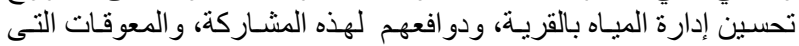

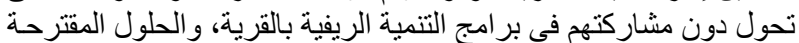

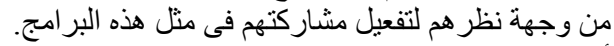
أسلوب تحليل البيانات :

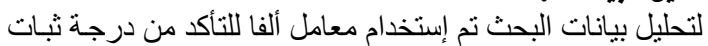

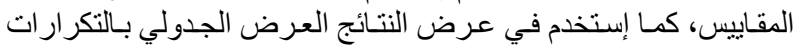

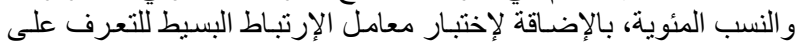
العلاقة بين متغير ات الدراسة. 


\section{Amany S. A. H. El Kholy}

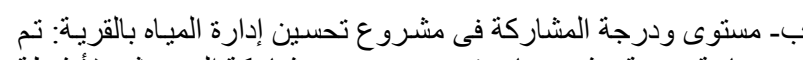

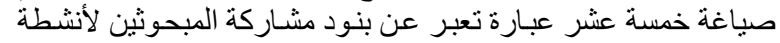

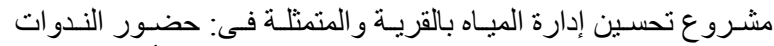

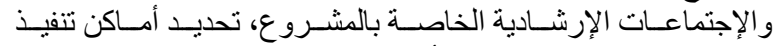

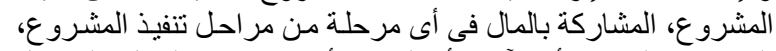

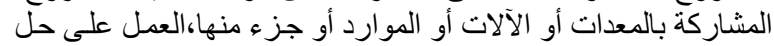

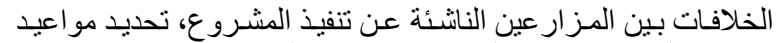

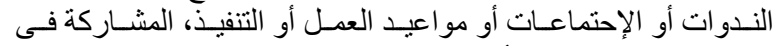

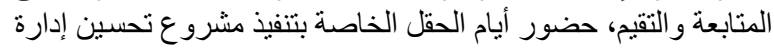

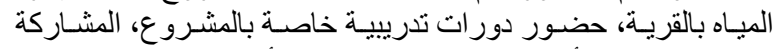

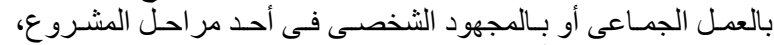

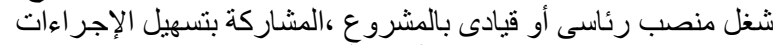

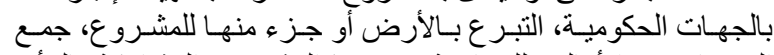

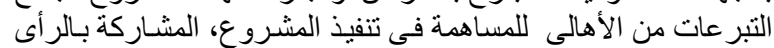

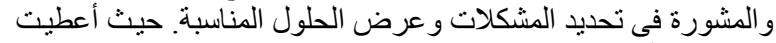

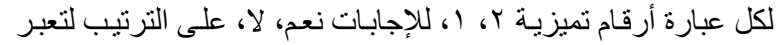

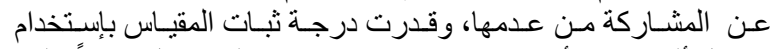

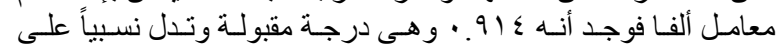

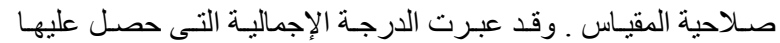

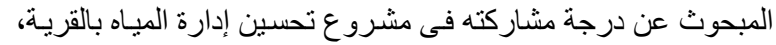

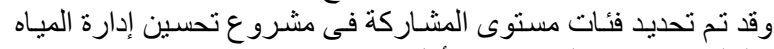

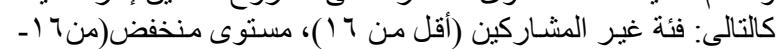

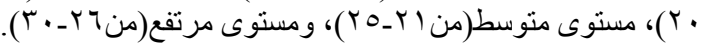

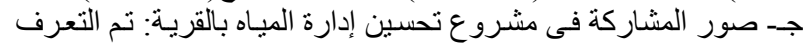

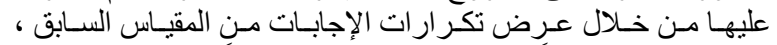

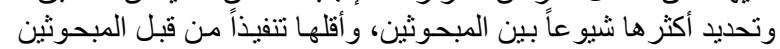
في مشرو ع تحسين إدارة المياه بالقرية.

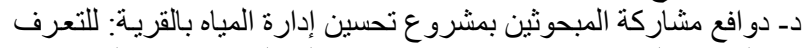

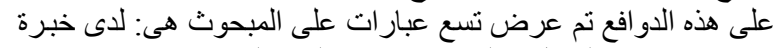

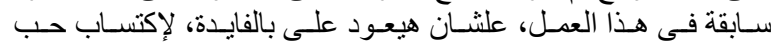

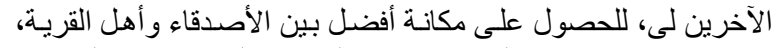

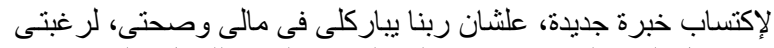

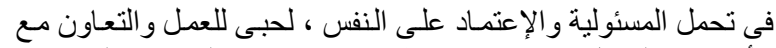

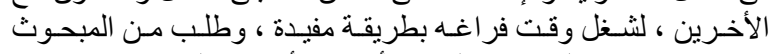

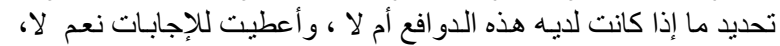

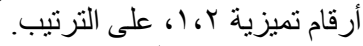

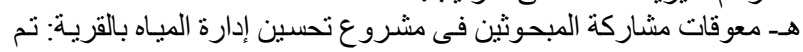

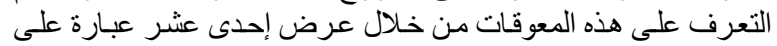

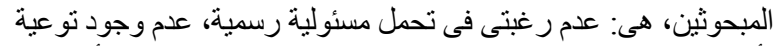

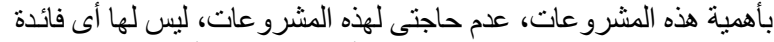

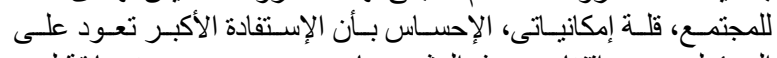

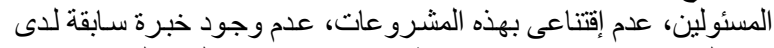

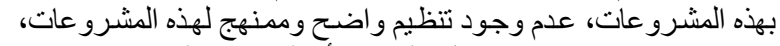

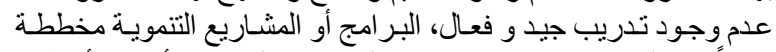

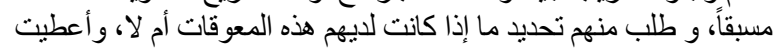

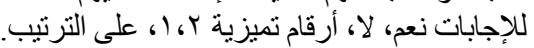

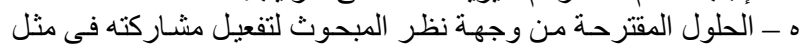

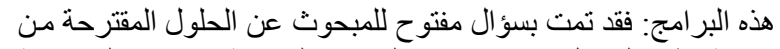

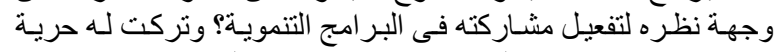

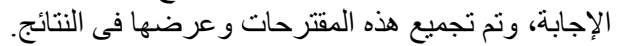

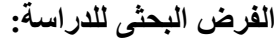

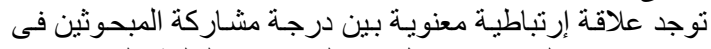

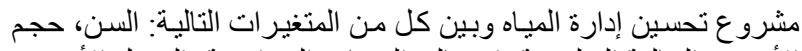

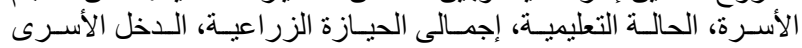

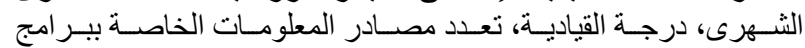

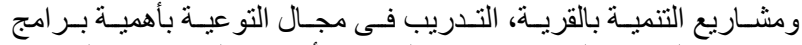

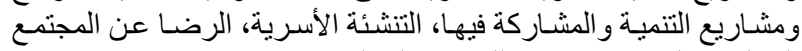
المحلى، والثعور بالإنتماء للمحتمع المحلى.

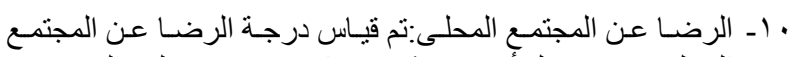

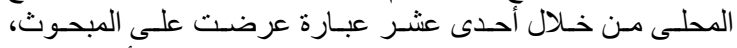

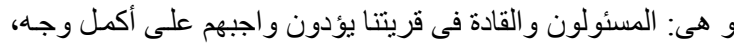

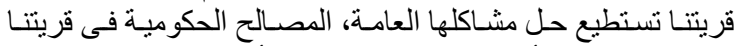

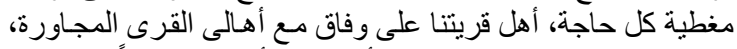

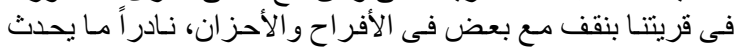

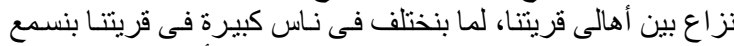

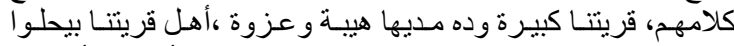

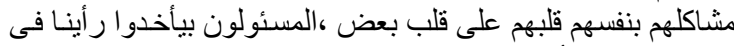

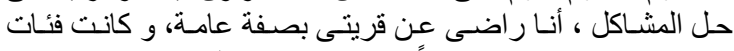

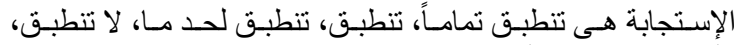

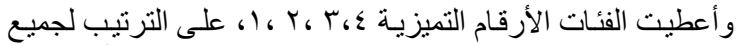

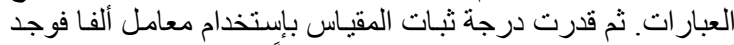

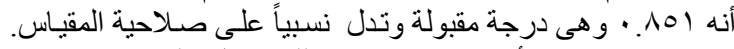

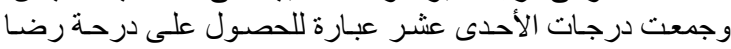

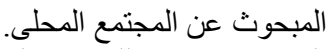

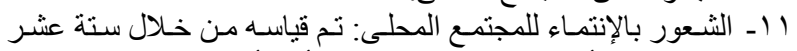

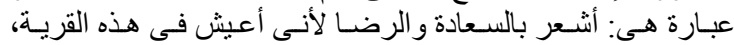

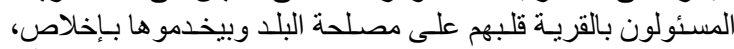

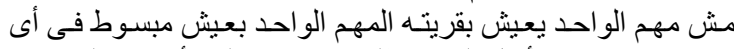

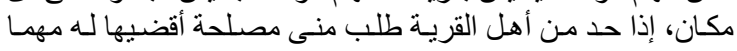

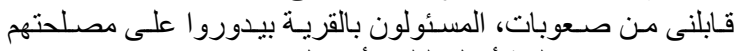

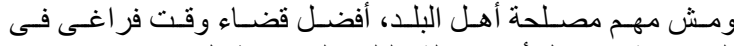

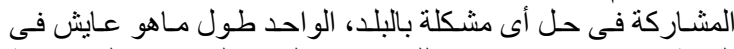

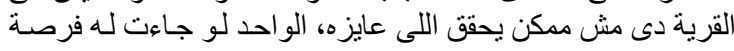

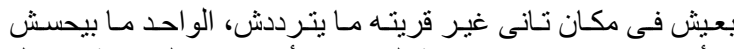

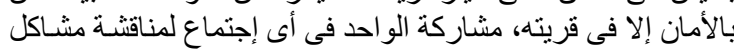

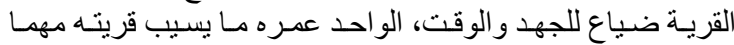

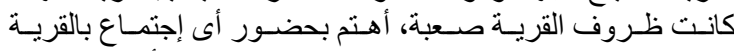

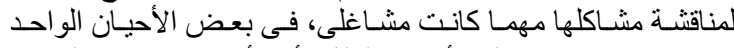

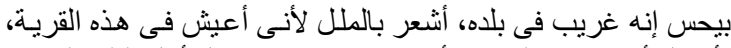

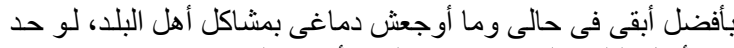

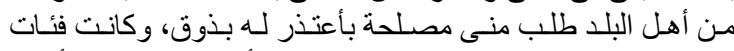

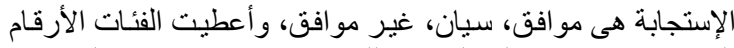

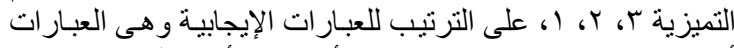

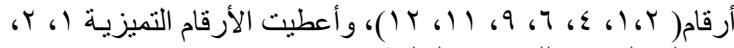

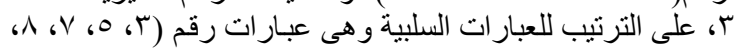

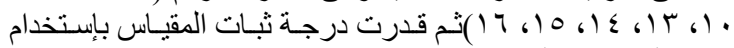

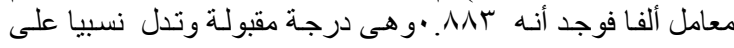

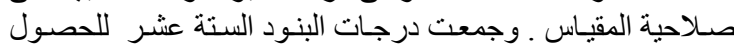

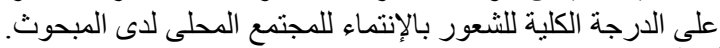

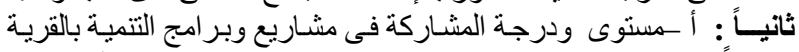

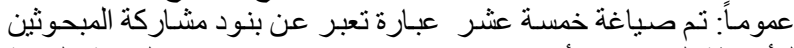

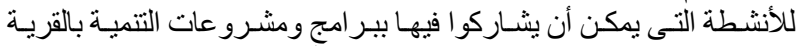

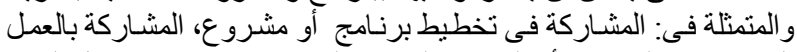

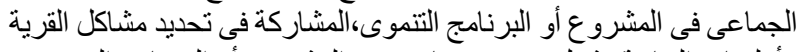

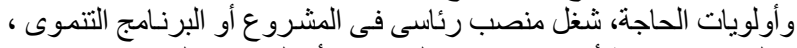

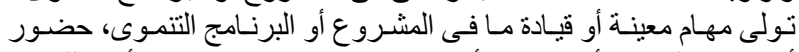

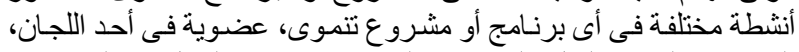

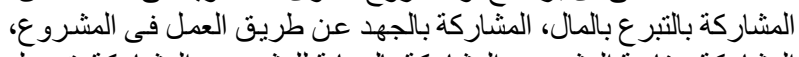

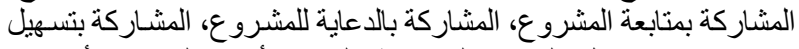

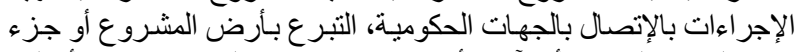

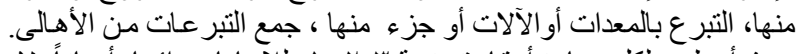

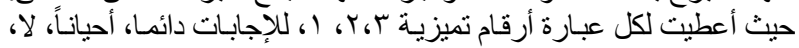

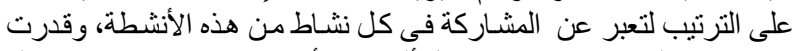

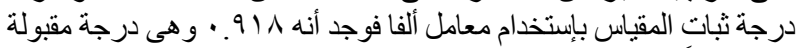

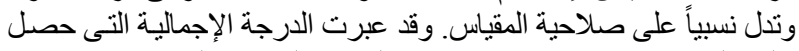

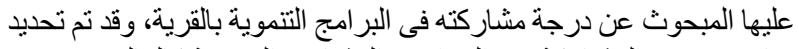

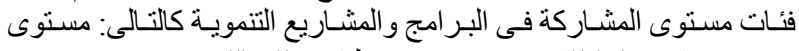

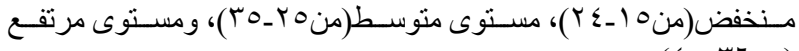




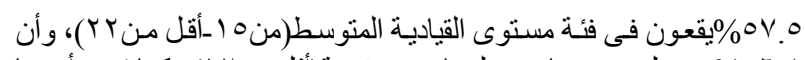

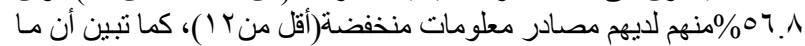

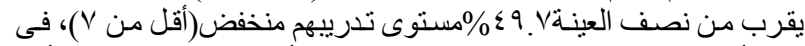

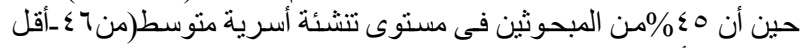

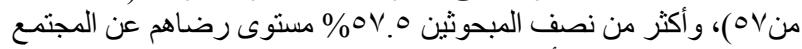

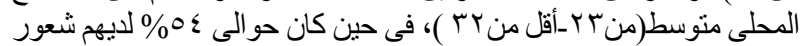

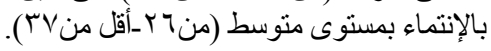

\section{النتائج البحثية}

أولاً: خصائص المبحوثين

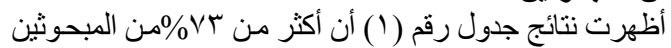

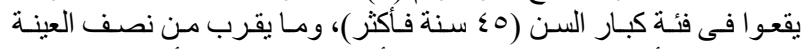

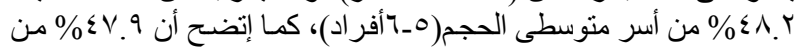

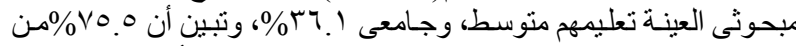

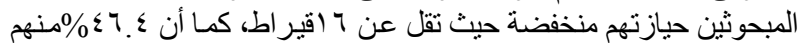

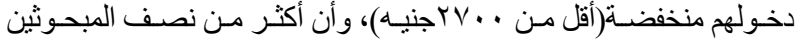

جدول رقم (1) توزيع المبحوثين وفقاً لمتغير اتهم الثخصية والإجتماعيةوالإقتصادية

\begin{tabular}{|c|c|c|c|c|c|c|c|c|}
\hline$\%$ & التكرار & التدريب & $\%$ & التكرار & الحيازة الزراعية & $\%$ & التكرار & السن \\
\hline ะ१.४ & 149 & 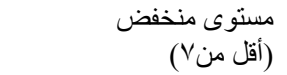 & or.o & 171 & حأقل من 7 اقفير اطة) & $r .7$ & 1. & (منبّاب_أفل منهr) \\
\hline rv. 1 & $V_{4}$ & مُستوى متوسط & ro.y & $1 .$. & حنيازة متوسطة 1 ـأقل كن بقير اط) & rT.r & 70 & مُتو سط العملر من \&) \\
\hline rT.r & 70 & (من_-فأكثر) & 7.1 & 19 & حنباز مرتفر اط_ فأكثر) & VT. & r.o & 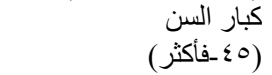 \\
\hline $1 .$. & rA. & الإجمالى & $1 \ldots$ & rA. & الإجمالى ل & $1 .$. & rA. & الإجمالى \\
\hline$\%$ & التكرار & التنشئة الأسرية & $\%$ & الت التكر ار & ال الدخل & $\%$ & التكرار & حجم الأسرة \\
\hline ד. & $9 \varepsilon$ & مستوى منخفض & $\leqslant 7 . \varepsilon$ & 14. & 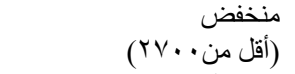 & 纟o & IrT & (أسلّ من هغيرة ادة \\
\hline \&o & Ir4 & 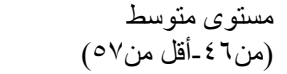 & r.o & 9) & 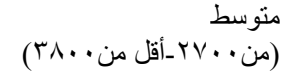 & $\varepsilon \Lambda, r$ & 1ro & أســــــ أفر داد) \\
\hline 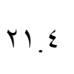 & 7. & مسنوى مرتفيع) & r.. & 09 & 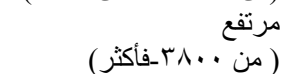 & $7 . \wedge$ & 19 & 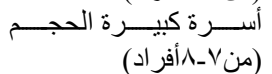 \\
\hline $1 \cdots$ & 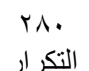 & الإضجمالى المجتمع الدحلى & $1 \ldots$ & 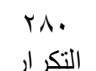 & الإجمالى & $1 \ldots$ & $\begin{array}{ll}r \lambda . \\
\text { r. }\end{array}$ & الحالةمالى التعليمبة \\
\hline ri.A & 19 & 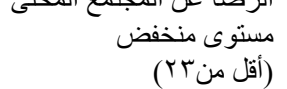 & $r .1$ & 09 & مستوى من أقفض من (10) & $r .7$ & i. & 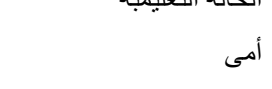 \\
\hline ov. o & 171 & 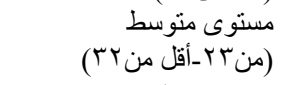 & ov.o & 171 & 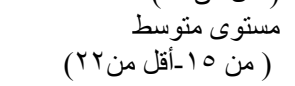 & $r .9$ & 1. & يقرأ ويكتب \\
\hline $1 \cdot . v$ & r. & مسنوى مرتكثرتح & $r . \varepsilon$ & 7. & مسنوى مرتفأكثر) & $\leqslant v .9$ & $1+\varepsilon$ & ت تعليم متوسط \\
\hline $1 \ldots$ & rA. & الإجمالى & $1 \ldots$ & rA. & الإجمالى & 4..1 & 1.1 & تعليم جامعى \\
\hline$\%$ & التكرار & الثعور بالإنتماء & $\%$ & التكرار & مصادر المعلومات & 1.9 & ro & تعليم فوق جامعى \\
\hline$? . \wedge$ & 19 & مستوى منخفض من (أق) & 07.1 & 109 & منخفض (أقل من ا) & $1 \ldots$ & rA. & الإجمالى \\
\hline or. 9 & 101 & 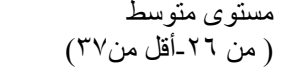 & r9.7 & 111 & 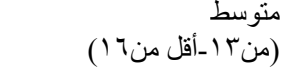 & & & \\
\hline $\begin{array}{l}r 9 . r \\
1 . .\end{array}$ & $\begin{array}{l}11 . \\
r \lambda .\end{array}$ & 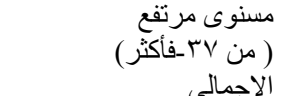 & $r .7$ & r. & 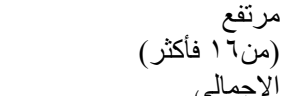 & & & \\
\hline
\end{tabular}

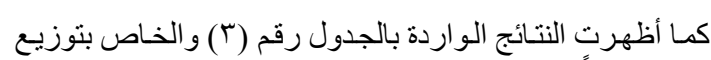

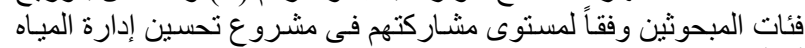

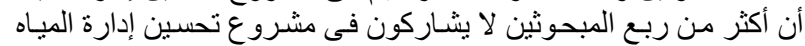

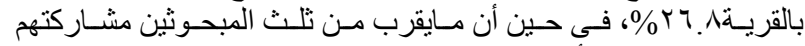

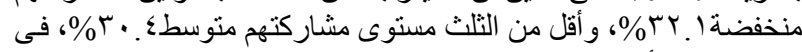

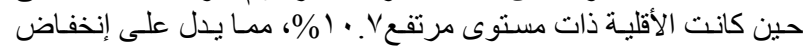

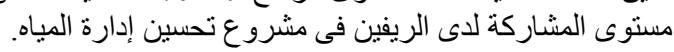

\begin{tabular}{|c|c|c|}
\hline النسبة المئوية & التكرار & مستوى المشاركة \\
\hline$r \tau . \wedge$ & Vo & غير المشاركين \\
\hline r.l & 9. & مستوى منخفض(من 7 ( - • Y) \\
\hline$r \cdot . \varepsilon$ & 10 & مستوى متوسط (من (Y_ Y Y ) \\
\hline $1 \cdot . V$ & ץ. & مستوى مرتفع (من ד - • (T) \\
\hline $1 \ldots$ & rᄉ. & الإجمالى \\
\hline
\end{tabular}

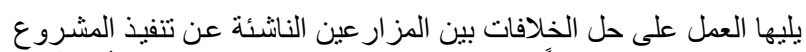

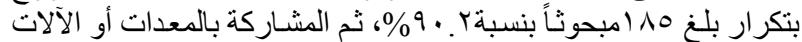

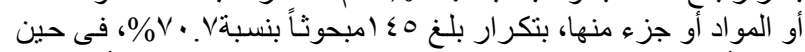

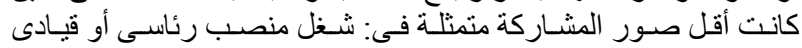

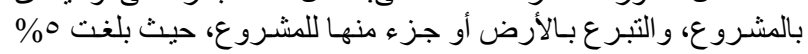

ثانياً: مستوى المشاركة وصور ها:

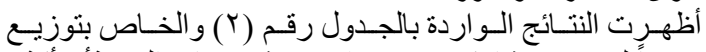

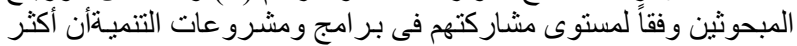

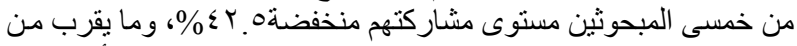

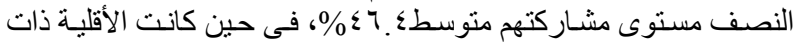

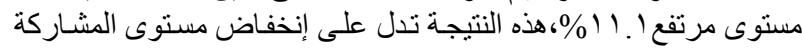
لاى الريفين فى بر امج التنمية الريفية بوجه النية عام. جدول رقم (r) توزيع فئات المبحوثين حسب مستوى فئم

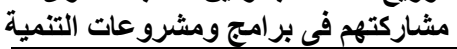

\begin{tabular}{|c|c|c|}
\hline النسبة المئوية & التكرار & مستوى المشاركة \\
\hline$\leqslant Y .0$ & 119 & منخفض(من 0 (Y) \\
\hline$\leqslant 7 . \leqslant$ & $1 T$. & متوسط(منهب_or) \\
\hline 11.1 & TI & مرتفع(من צr_ §) \\
\hline $1 \ldots$ & rA. & \\
\hline
\end{tabular}

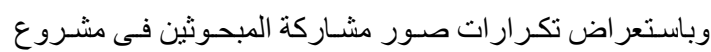

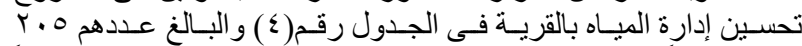

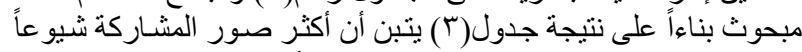

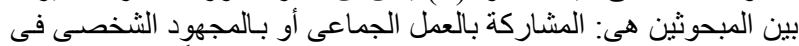

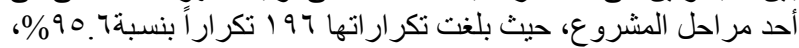




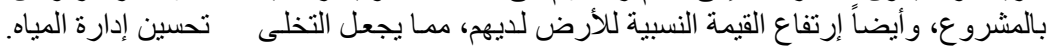

جدول رقم (ع) توزيع المبحوثين وفقاً لتكرارات صور مشاركتهم في مشروع تحسين إدارة المياه

\begin{tabular}{|c|c|c|c|}
\hline 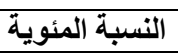 & 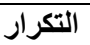 & صور المشاركة" & 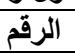 \\
\hline 90.7 & 197 & المشاركة بالعمل الجماعى أو بالمجهود الثخصى فى أحد مر احل المشروع & 1 \\
\hline $9 \cdot . r$ & 110 & العمل على حل الخلافات بين المزار عين الناشئة عن تنفيذ المشروع & r \\
\hline$v \cdot . v$ & $1 \leqslant 0$ & المشاركة بالمعدات أو الآلات أو المو اد أو جزء منها & r \\
\hline $7 \wedge$. & $1 \leqslant$. & جمع التبر عات من الأهالى & $\varepsilon$ \\
\hline $0 \wedge .0$ & ir. & المشّاركة بالر أى و المشورة فى تحديد المشكلات وعرض الحلول المناسبة & ○ \\
\hline 07.1 & 110 & حضور أيام الحقل الخاصة بتنفيذ المشروع & 7 \\
\hline$\varepsilon \wedge . \wedge$ & $1 \cdots$ & حضور الندوات والإجتماعات الإرشادية & 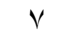 \\
\hline$\leqslant 1.0$ & 10 & المشاركة في المتابعة و التقيم & $\wedge$ \\
\hline rч. & 00 & حضور دورات تدريبية خاصة بالمشروع & 9 \\
\hline 19.0 & $\varepsilon$. & المشاركة بالمال فى أى مرحلة من مر احلّ تنفيذ المشروع & $1 \cdot$ \\
\hline 19.0 & $\varepsilon$. & المشاركة بتسهيل الإجر اءات بالجهات الحكومية & 11 \\
\hline $1 V_{.} \mid$ & קo & تحديد أماكن تنفيذ المشروع & ir \\
\hline $1 \leqslant .7$ & r. & تحديد مو اعيد الندوات أو الإحتماعات أو مو اعيد العمل أو التنفيذ & ir \\
\hline$\varepsilon .9$ & 1 . & التبرع بالأرض أو جز ء منها للمشروع & $1 \varepsilon$ \\
\hline$\varepsilon .9$ & $1 \cdot$ & شغل منصب رئاسى أو قيادى بالمشروع & 10 \\
\hline
\end{tabular}

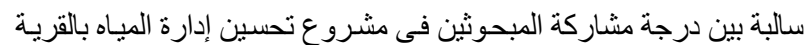

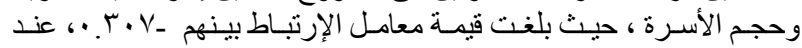

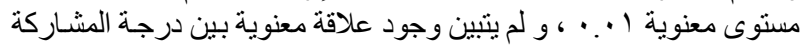

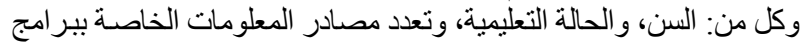

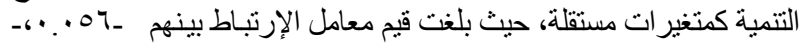

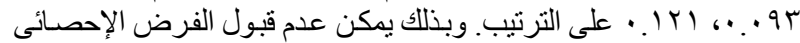

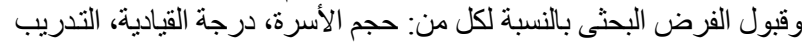

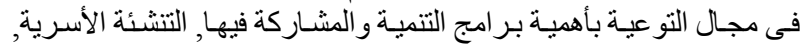

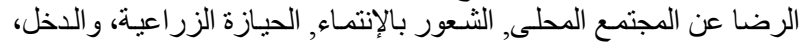

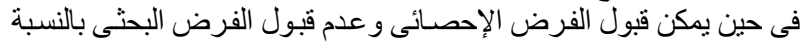

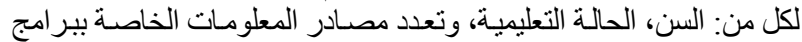

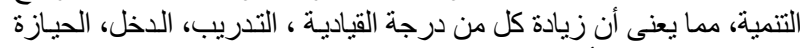

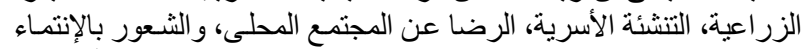

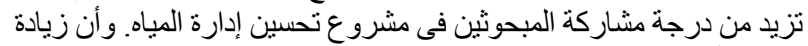

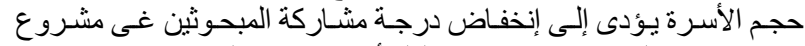

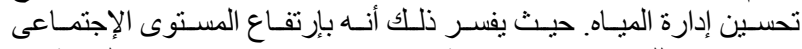

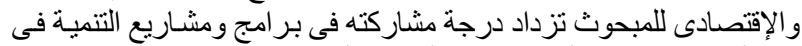

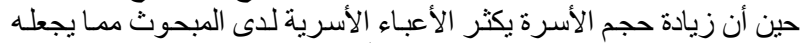
يوجه كل طاقته و أمو اله لر عاية أسرته أو لاًا.

ثالثثاً: العلاقة بين خصـائص المبحوثين المدروسـة ودرجة مشـاركتهم فى بـ إلى مشروع تحسين إدارة المياه بالقرية:

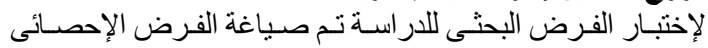

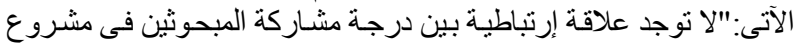

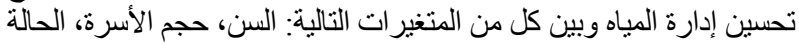

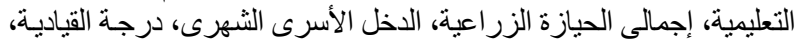

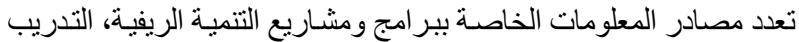

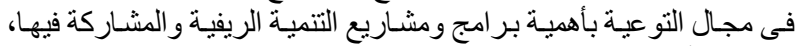

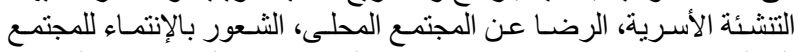

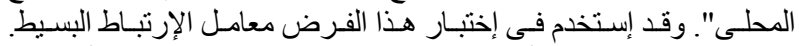

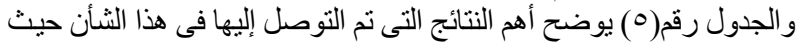

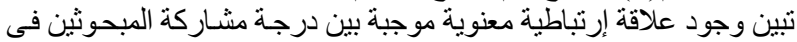

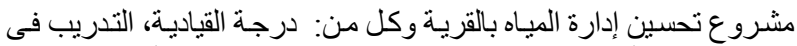

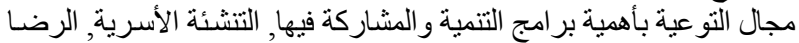

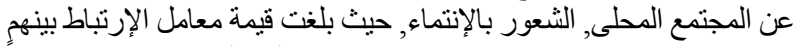

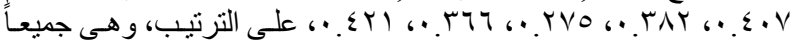

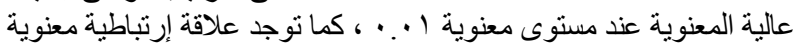

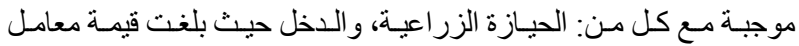

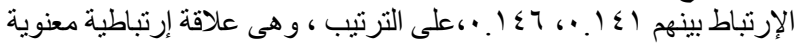

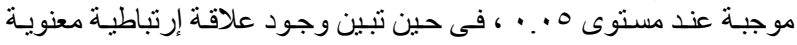
جدول رقم ( •) العلاقة الإرتباطية بين خصائص المبحوثين المدروسة ودرجة مشاركتهم في مشروع تحسين إدارة المياه

\begin{tabular}{|c|c|c|}
\hline 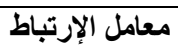 & خصائص المبحوثين المدروسة & 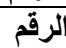 \\
\hline$\because .07$ & السن & 1 \\
\hline$* * \cdot r \cdot v_{-}$ & حجم الأسرة & r \\
\hline$\because I Y V_{-}$ & الحالة التعليمية & r \\
\hline$* .1 \leq 1$ & الحيازة الزراعية & $\varepsilon$ \\
\hline$* .1 \leq 7$ & 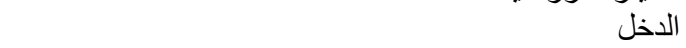 & 0 \\
\hline$* * \cdot \varepsilon \cdot v$ & 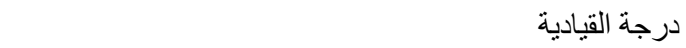 & 7 \\
\hline. $.1 Y 1$ & تعدد مصادر المعلومات الخاصة ببرامج التنمية & $\checkmark$ \\
\hline **. rᄉr & التدريب فى مجال التو عية بأهمية بر امج التنمية و المشاركة فيها & $\wedge$ \\
\hline$* *$. rVo & التنشئة الأسرية ل & 9 \\
\hline **. & الرضا عن المجتمع المحلى & 1. \\
\hline$* * . . \leq Y$ & الشعور بالإنتماء & 11 \\
\hline
\end{tabular}

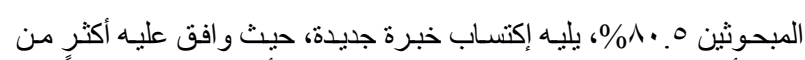

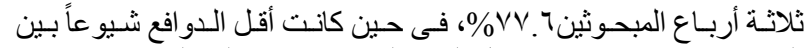

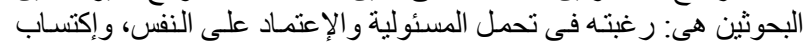

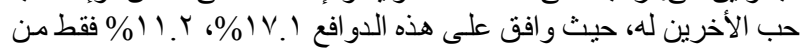

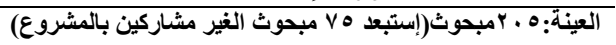

رابعاً: التعرف على الدوافع والمعوقات والمقترحات

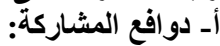

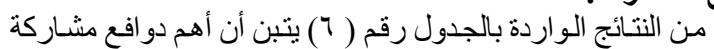

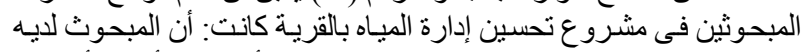

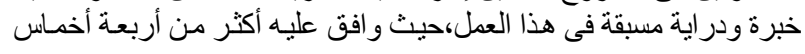


جدول رقم (†) توزيع المبحوثين وفقاً لتكرارات دوافع مشاركتهم فى مشروع تحسين إدارة المياه

\begin{tabular}{|c|c|c|c|}
\hline النسبة المئوية & 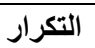 & 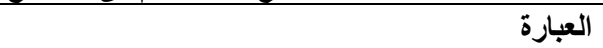 & الرقم \\
\hline$\Lambda \cdot .0$ & 170 & لاى خبرة سابقة فى هذا العمل & 1 \\
\hline$V \vee .7$ & 109 & لإكتساب خبرة جديدة & r \\
\hline $71 . \wedge$ & $1 \leq 1$ & علشان هيعود على بالفايدة & r \\
\hline$\varepsilon r$ & $\wedge 7$ & لحبى للعمل و التعاون مع الأخرين & $\varepsilon$ \\
\hline ro. & Vr & علثان ربنا يباركلى فى مالى وصحتى & 0 \\
\hline r. & 79 & لشغل وقت فر اغة بطريقة مفيدة & 7 \\
\hline M. r & $7 \varepsilon$ & للحصول على مكانة أفضل بين الأصدقاء و أهل القرية & v \\
\hline $\mid v .1$ & ro & 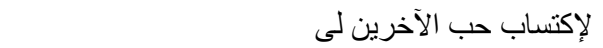 & $\wedge$ \\
\hline $11 . r$ & r & لر غبتى فى تحمل المسئولية والإعتماد على النفس & 9 \\
\hline
\end{tabular}

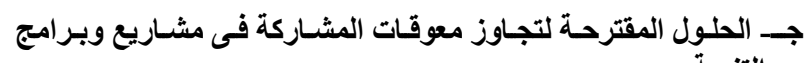
التنمية:

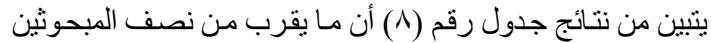

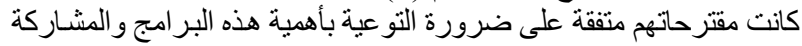

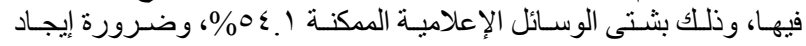

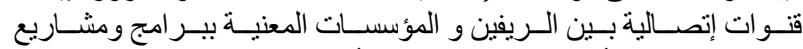

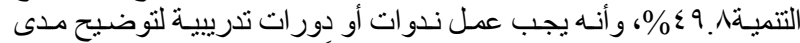

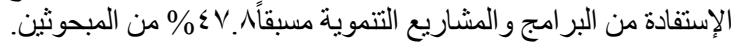

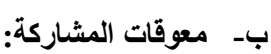

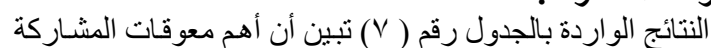

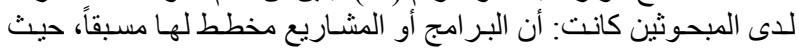

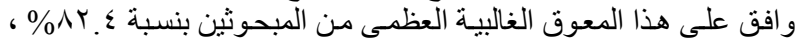

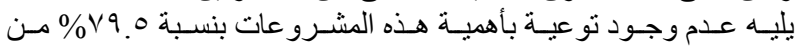

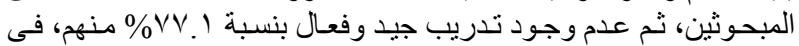

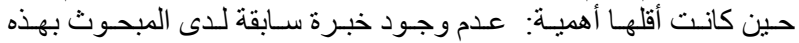

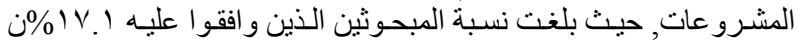

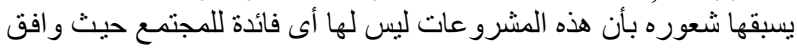

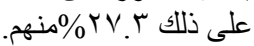

جدول رقم (V) توزيع المبحوثين وفقاً لتكرارات معوقات مشاركتهم فى مشروع تحسين إدارة المياه *(العينة هـr. بمبحوثاً)

\begin{tabular}{|c|c|c|c|}
\hline النسبة المئوية & 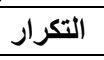 & العبارة & 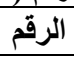 \\
\hline$\Delta r . \varepsilon$ & 179 & البرامج أو المشاريع التتموية مخططة مسبقاً & 1 \\
\hline v9.0 & $17 \pi$ & عدم وجود تو عية بأهمية هذه المشرو عات & r \\
\hline VV.1 & 101 & عدم وجود تدريب جيد و فعال & r \\
\hline 77.1 & Irt & عدم وجود تنظيم واضح وممنهج لهذه الهشرو عات & $\varepsilon$ \\
\hline $7 r .9$ & $1 r^{9}$ & الإحساس بأن الإستفادة الأكبر تعود على المسئولين & $\circ$ \\
\hline $0 \leqslant .7$ & 114 & عدم رغبتى فى تحمل مسئولية رسمية & 7 \\
\hline$\varepsilon \wedge . r$ & 99 & قلة إمكانياتى ق ق ق & $v$ \\
\hline rv. & VT & عدم حاجتى لهذه المشرو عات & $\wedge$ \\
\hline$r \cdot . r$ & $\leq 9$ & عدم إقتناعى بهذه المشروعات & 9 \\
\hline$r r^{\prime} r$ & 07 & 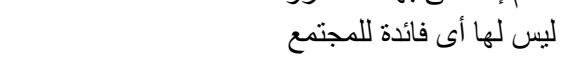 & 1. \\
\hline IV.1 & ro & عدم وجود خبرة سابقة لدى بهذه المشرو عات & 11 \\
\hline
\end{tabular}

جدول رقم (^) توزيع المبحوثين وفقاً لتكرارات مقترحاتهم لتفعيل المشاركة في مشاريع ويرامج التنمية

\begin{tabular}{|c|c|c|c|}
\hline النسبة المئوية & التكرار & العبارة & الرقم \\
\hline $0 \leqslant .1$ & 111 & ضرورة التو عية بأهمية هذه البرامج و المشاركة فيها، وذلك بشتى الوسائل الإعلامية الممكنة & 1 \\
\hline$\leqslant 9 . \wedge$ & $1 . r$ & ضرورة إيجاد قنوات إتصالية بين الريفين و المؤسسات المعنية ببر امج التتمية & r \\
\hline$\leqslant v . \wedge$ & 91 & عمل ندو ات أو دور ات تدرييية لتوضيح مدى الإستفادة من البرامج و المشاريع التتموية مسبقاً & r \\
\hline rᄉ. 0 & v & 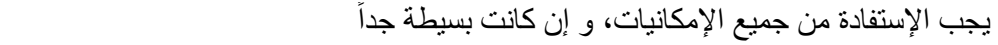 & $\varepsilon$ \\
\hline$\Gamma \leq .7$ & v) & يجب أن يكون التنريب جيد وفعال(عملى و ليس نظرى فقط) & ० \\
\hline ru.r & 74 & يجب السماح للريفين بإبداء الرأى، و إن كان معارضاً & 1 \\
\hline
\end{tabular}

المشروع أو البرنـامج بفترة كافية، ومتضمنه تدريباً عملياً يبين مدى المقى

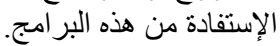

\section{المراجع}

ع-ضرورة الإهتمام برفع مستوى الإن

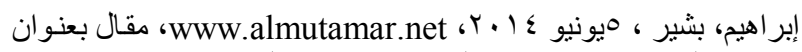

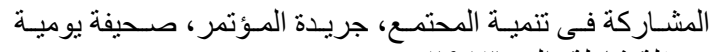

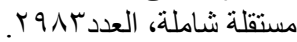

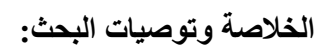

أكدت نتائج البحث، و والمشيات البحث: إليها سابقاً على مايلى:-

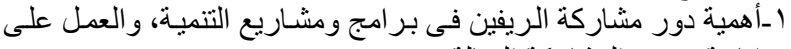

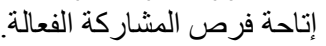

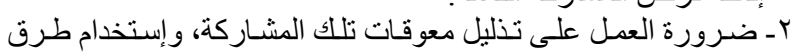

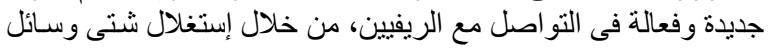

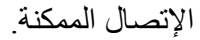

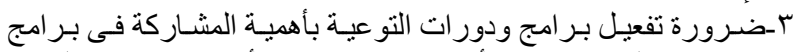

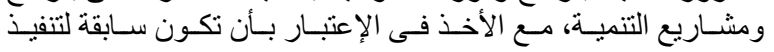




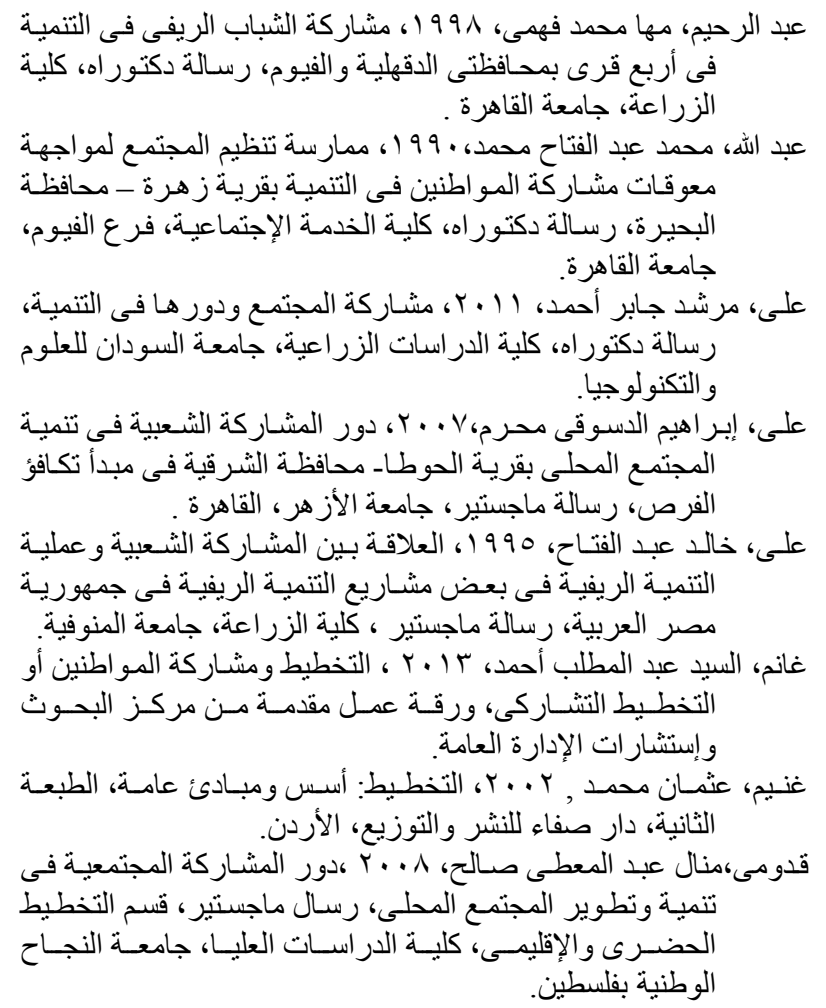

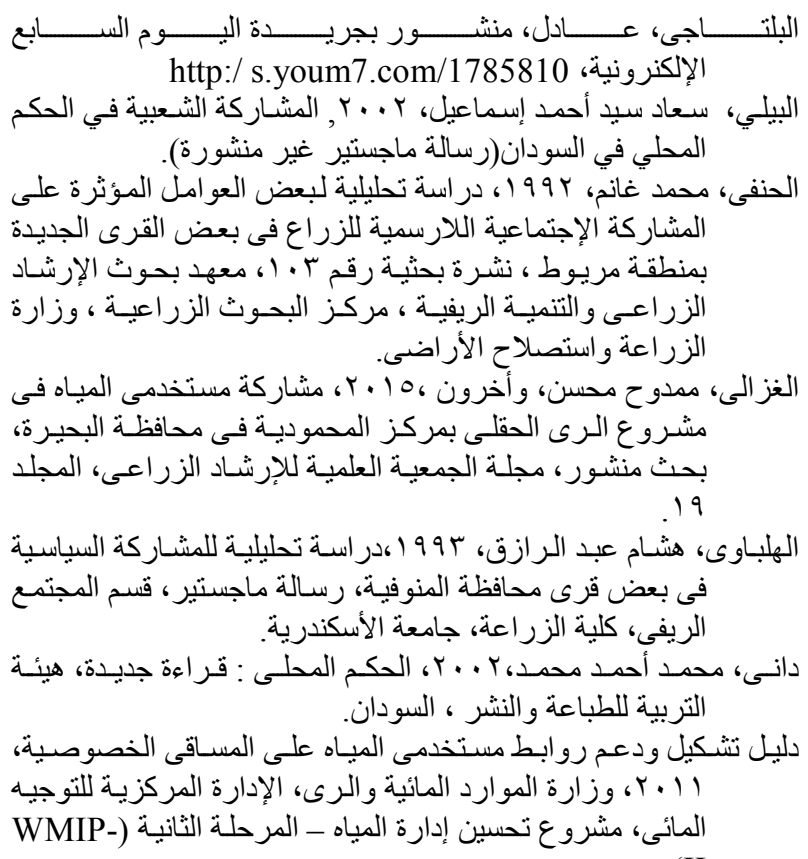

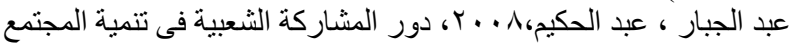

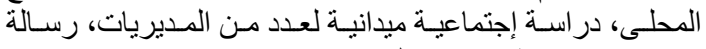
ماجستير ، جامعة صنعاء، اليمن .

\title{
Some Factors Affecting the Rural People Participation in the Rural Development Programs and Projects in Some Villages of El-Gharbia Governorate (Model: Water Management Improvement Project)
}

\author{
Amany S. A. H. El Kholy
}

Researcher, Department of Rural Community Research, Agricultural Extension \& Rural Development Research Institute, Agricultural Research Center.

\begin{abstract}
Great deals of research effort in the field of rural projects development were applied in recent times. The majority of these efforts tend to study the factors that affect the participation of rural people in the programs and projects of rural development. In this context, this study aimed to determine the participation level of rural people in the Water Management Improvement Project (WMIP), to identifying the relationship between the degree of respondents' participation in WMIP and their socioeconomic characteristics, also identifying the kind of their participation in this project, in addition to, identifying the motives for their participation, identifying the obstacles that prevent their participation, and their attitude in solving to activating their participation in WMIP. This research was implemented in three villages from three different districts of Gharbia Governorate; the systematic random sample was involved two hundred and eighty respondents (280). The data were collected using a questionnaire by personal interview during January 2016. Frequencies, percentages, alpha coefficient, and simple correlation analysis were used as statistical techniques. The results revealed a low level of participation in the WMIP (32.1\%) and most implementation among the respondents are the participation in collective action or personal effort $(73.2 \%)$, solving the differences between farmers which about implementation of the project $(66.1 \%)$, then the participation by equipments, machineries or materials $(51.8 \%)$, and the collecting donations from the people $(50 \%)$. In addition, the results indicate that there are positive significant relationships between the respondent's participation degree in WMIP and the following socioeconomic characteristics: the degree of leadership, training to awareness of the importance of development, family upbringing, satisfaction with the local community, and a sense of belonging to the community; while the results showing a negative significant relationship between the respondent's participation degree in WMIP and the family size. The important motivations of respondent's participation in WMIP were: the experience and previous knowledge in this work and gain new experiences. The most important obstacles to participate in WMIP were that planned project in the past without the knowledge of the people in rural area and the lack of awareness of the importance of the project. The respondents mentioned that the important attitudes in solving activating their participation were: the necessity to raise awareness of the importance of these projects by all media kind and create communication channels between rural people and institutions that working on development projects to activate them to participate in the same projects.
\end{abstract}

